\title{
AN IMPROVED STAPLER
}

\author{
G. M. MÜLler, London, ENGLAND
}

From the Institute of Orthopaedics, Royal National Orthopaedic Hospital

This stapler* was designed to meet the need for an easy and effective means of stapling in order to control epiphysial growth, particularly at the knee. Essentially it is a double-ended punch which will hold, at one or other end, staples of any size suitable for bridging the lower femoral or upper tibial epiphysis.

The punch, knurled for firm grip, is seven inches long and has a diameter of 5.5 inch. One end, for a distance of an inch, is expanded to a diameter of $\frac{7}{8}$ inch. Each end bears a

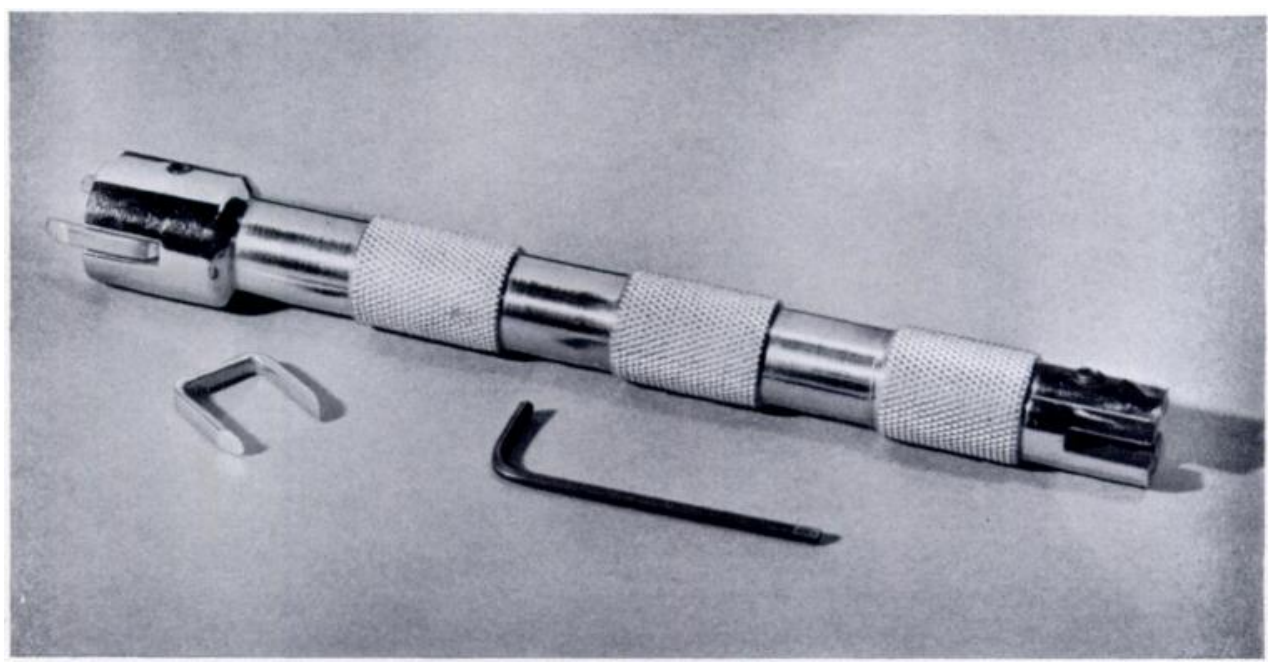

FIG. 1

slot, $\frac{9}{16}$ inch deep, in which a staple may be gripped by turning a grub screw about 60 degrees with a wrench key. At right angles to this slot there is provided, at the smaller end, a slot ${ }_{32}^{9}$ inch deep, and at the larger end, a shallow groove.

When the instrument is used, a staple, held in the deep slot of the appropriately sized end, is driven into the bone half-way home with a mallet. The screw is relaxed, and the ${ }_{32}^{9}$ inch slot, instead of the deep slot, is made to engage with the staple so that it can be driven farther. Finally, using the shallow groove, the staple is driven fully home.

The type of staple under trial is oblong in section and has chisel ends with the bevel on the outside. This is thought to have an advantage over staples of round section because a greater surface of each staple is opposed to the forces of growth, so that two staples might do the work of the three round staples generally used at each edge of an epiphysial plate.

* The instrument and staples are made by the London Splint Company Ltd., 69 Weymouth Street, London, W. 1. 